Hansen, J. B. \& Gibson, R. E. (1949). Undrained shear strength of anisotropically consolidated clays, Géotechnique 1, No. 3, 189-204.

Ingles, O. G. \& Lee, I. K. (1971). The influence of initial grain shape and pore anisotropy on strength of brittle soils. Géotechnique 21, No. 2, 143-153.

Khera, R. P. (1967). Strength response of anisotropically consolidated clays. PhD thesis, Western University, Illinois.

Sankaran, K. S. \& Bhaskaran, R. (1972a). Strength anisotropy in cohesive soils. To be published in Proc. Symp. Modern Trends in Civil Engineering 1, Roorkee, Oct.

Sankaran, K. S. \& Bhaskaran, R. (1972b) Private communication.

Skempton, A. W. \& Hutchinson, J. (1969). Stability of natural slopes and embankment foundation, State of art report, 7th Int. Conf. Soil Mech., Mexico. State of art volume, 308-332.

\title{
The consolidation of soils exhibiting creep under constant effective stress
}

GARLANGER, J. E. (1972). Géotechnique 22, No. 1, 71-78.

\section{Suklje, University of Ljubljana, Yugoslavia}

Based on the soil model described by Bjerrum (1967), Garlanger has expressed the void ratio change corresponding to an increase of effective pressures from $p_{0}$ to $\sigma^{\prime}$, according to the strain path OAB when $\sigma^{\prime} \leqslant p_{\mathrm{c}}$, and OCDE when $\sigma^{\prime} \geqslant p_{\mathrm{c}}$ (Fig. 1). In the latter case, at a time $t$ after the end $\left(t_{\mathrm{i}}\right)$ of the increase of effective stress up to $p_{\mathrm{f}}$, the void ratio change has been presented by the equation

$$
\frac{e}{e_{0}}=\left(\frac{p_{\mathrm{c}}}{p_{0}}\right)^{-a}\left(\frac{p_{\mathrm{f}}}{p_{\mathrm{c}}}\right)^{-b}\left(\frac{t_{\mathrm{i}}+t}{t_{1}}\right)^{-c}
$$

$a$ and $b$ being the respective slopes of the lines $\mathrm{OC}$ and $\mathrm{CD}$. Garlanger considers that the stress $p_{\mathrm{f}}=p$ is a time dependent variable. Consequently

$$
\frac{\partial e}{\partial t}=\frac{\partial e}{\partial p} \frac{\partial p}{\partial t}+\left(\frac{\partial e}{\partial t}\right)_{c}
$$

where

$$
\frac{\partial e}{\partial p}=\frac{b e}{p}
$$

and

$$
-\left(\frac{\partial e}{\partial t}\right)_{\mathrm{c}}=\left(\frac{c e}{t_{\mathrm{i}}}\right)\left(\frac{e}{e_{\mathrm{c}}}\right)^{1 / c}\left(\frac{p}{p_{\mathrm{c}}}\right)^{b / c}
$$

with $p \equiv \sigma^{\prime}$ according to the notation in Fig. 1. When $p \leqslant p_{\mathrm{c}}$, equation (1) reduces to

$$
\frac{e}{e_{0}}=\left(\frac{p}{p_{0}}\right)^{-a}\left(\frac{t_{1}+t}{t_{1}}\right)^{-c}
$$

In this case, Garlanger has obtained

$$
-\frac{\partial e}{\partial p}=\frac{a e}{p}
$$

However, at $\sigma^{\prime} \leqslant p_{\mathrm{c}}$ the time $t_{\mathrm{i}}$ has to be considered a stress dependent parameter and so equation (3) is regained for $\partial e / \partial p$.

If one assumes a sudden cffective stress increase, the slope $a$ becomes zero and the strain paths $\mathrm{OAB}$ and OCDE have to be replaced by respective strain paths OFB and OGE (Fig. 1). 


\section{Fig. 1. Time lines}

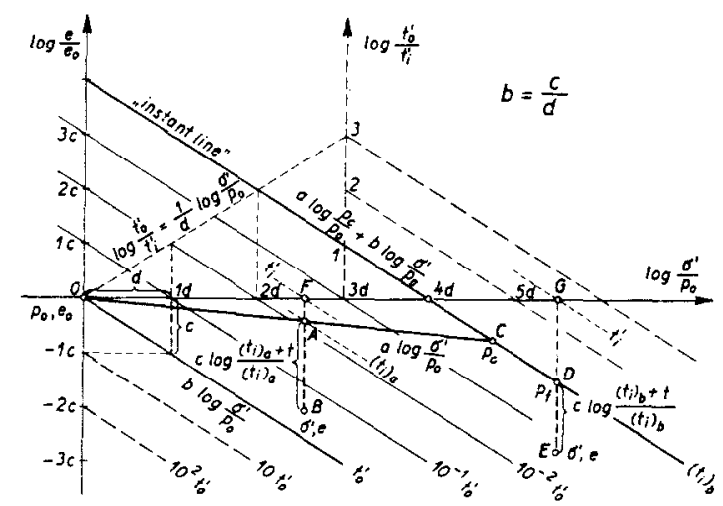

Extrapolating the time lines

$$
e=\left[e\left(\sigma^{\prime}\right)\right]_{t_{1}=\text { constant }}
$$

beyond the 'instant line', the void ratio change, in both cases, can be expressed only by the equation

$$
\frac{e}{e_{0}}=\left(\frac{t^{\prime}}{t^{\prime}}\right)^{-c}
$$

where

$$
t^{\prime}=t_{1}^{\prime}+t
$$

and, according to Fig. 1,

$$
t_{1}^{\prime}=t_{0}^{\prime}\left(\frac{p_{0}}{\sigma^{\prime}}\right)^{1 / d}
$$

Thus equation (7) can be written

$$
e=\left(A t^{\prime} \sigma^{\prime 1 / d}\right)^{-\mathrm{c}}
$$

$A$ being an invariant of the $\left(e, \sigma^{\prime}, t^{\prime}\right)$ system

$$
A=\left(e_{0}{ }^{1 / c} p_{0}{ }^{1 / d} t^{\prime}{ }_{0}\right)^{-1}=\left(e^{1 / c} \sigma^{\prime 1 / d} t^{\prime}\right)^{-1}
$$

If the stress $\sigma^{\prime}$ is considered a time dependent variable, the differentation of equation (10) yields

$$
-\dot{e}=c e\left(A e^{1 / c} \sigma^{\prime 1 / d}+\frac{1}{d} \frac{1}{\sigma^{\prime}} \frac{\partial \sigma^{\prime}}{\partial t^{\prime}}\right)
$$

Considering that

$$
\frac{b}{c}=\frac{1}{d}
$$

and

$$
\left(t_{\mathrm{i}} e_{\mathrm{c}}{ }^{1 / c} p_{\mathrm{c}}{ }^{b / c}\right)^{-1}=A
$$

the first member of equation (12) is identical to Garlanger's equation (4), and the second member identical to $(\partial e / \partial p)(\partial p / \partial t)$ with $\partial e / \partial p$ according to equation (3).

Now, the validity of the respective equations (1) and (5), and (7) and (10) was experimentally verified only under the condition

$$
\frac{\partial p}{\partial t}=\frac{\partial \sigma^{\prime}}{\partial t^{\prime}} \rightarrow 0
$$




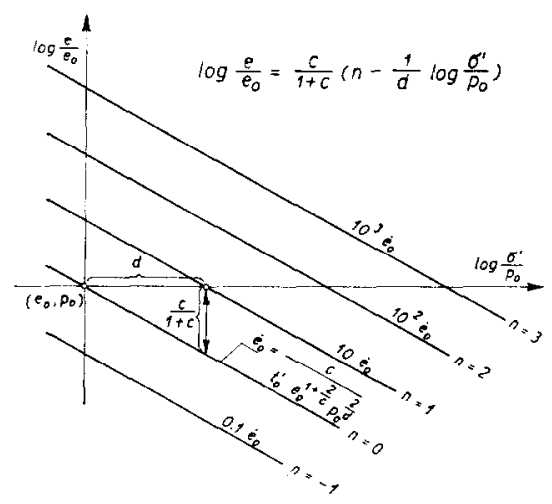

Fig. 2. Isotaches

In this case, the second member in equation (12) disappears and the remaining term

$$
-\dot{e}=c A e^{(\mathrm{c}+1) / \mathrm{c}} \sigma^{1 / d}
$$

represents the 'isotache' set (Šklje, 1957) of the special rheological scheme according to Fig. 1. This set is shown in Fig. 2. By introducing equation (16) into the Terzaghi-Biot differential equation of consolidation, the solution is obtained for arbitrary boundary conditions concerning: $(a)$ the initial $\left(e, \sigma^{\prime}\right)$ values varying with the coordinate $z ;(b)$ the magnitude of the applied load and $(c)$ the speed of the load application. Examples of such numerical analysis of the consolidation process have been given in several publications (Šuklje and Kogovšek, 1968; Suklje, 1969a and b; Battelino, 1970; Šuklje and Simončič, 1972; Šuklje and Kozak, 1972) and different expressions $e=e\left(\dot{e}, \sigma^{\prime}\right)$ for isotaches have been used corresponding to deformability tests of various specimens.

For the construction of isotaches the time lines $e=\left[e\left(\sigma^{\prime}\right)\right]_{t_{i}}=$ constant (Fig. 1) are not needed. They can be obtained from the consolidation lines (preferably from secondary consolidation branches) in the way explained in previous publications (Šuklje, 1957 and 1969a). To avoid structural disturbance a slow, continuous load application is recommended interrupted by the long-term observation of the sccondary consolidation at certain total stresses $\sigma$.

Berre and Iversen (1972; companion paper) have found good agreement of experimental time-compression curves with theoretical curves according to the theory of Barden (1965) in which the soil skeleton is represented by a spring coupled in parallel with a non-linear dashpot. The predicted pore pressures were, especially for the lowest specimens, too low at small values of time; they are better, the higher the specimen. The rheological relationships of the nonlinear Kelvin model of Barden's theory can be expressed by parallel straight isotaches

$$
e=\left[e\left(\sigma^{\prime}\right)\right]_{\mathrm{e}=\text { constant }}=\left(e_{2}+a \sigma\right)-a \sigma^{\prime}-b e^{0 \cdot 1 / n}
$$

and

$$
e_{2}+a \sigma=\text { constant }
$$

The speed of the effective stress change $\dot{\sigma}^{\prime}$ does not influence the consolidation process. According to Berre and Iversen's comparison of experimental and theoretical consolidation curves, the speed $\dot{\sigma}^{\prime}$ does not seem to affect the consolidation of natural layers of soil whose thickness is of the order of magnitude of $1 \mathrm{~m}$ or more and whose properties are similar to those treated in both companion papers.

Garlanger requires that right after a sudden load application the additional effective stresses should be zero $\left(\mu_{1}=1 \cdot 0\right)$, except at the drainage boundary. In the case of viscous soils, this requirement is not justified. It seems to be because of a wrong application of the classical 
principle of effective stresses to viscous soils. Whether, after a sudden load application, the consolidation will start at zero additional effective stresses depends on the initial porosity (consolidation speed respectively), the permeability, the loading interval and the drainage path (layer thickness). The interpretation, proofs and examples of the above statement have been given elsewhere, e.g. Šuklje, 1957, 1969 (a and b); Šuklje and Simončič, 1972.

\section{REFERENCES}

Barden, L. (1965). Consolidation of clay with non-linear viscosity. Géotechnique 15, No. 4, 345-362.

Battelino, D. (1970). Contribution to the investigation of the consolidation of saturated soils exhibiting non-linear, anisotropic and viscous deformability (in Slovenian with summary in English). University of Ljubljana, Acta Geotechnica, No. 30, 1-25.

Berre, T. \& Iversen, K. (1972). Oedometer tests with different specimen heights on a clay exhibiting large secondary compression. Géotechnique 22, No. 1, 53-70.

Bjerrum, L. (1967). Seventh Rankine Lecture. Engineering geology of normally-consolidated marine clays as related to settlements of buildings. Géotechnique 17, No. 2, 82-118.

Suklje, L. (1957). The analysis of the consolidation process by the isotache method. Proc. 4th Int. Conf. Soil Mech., London 1, 200-206, and 3, 116-119.

Šuklje, L. \& Kogovšek, B. (1968). Isochrones of a uniformly loaded layer of viscous soils. III Sesja Naukowa Wydzialu Budownictva Ladovego Politechniki Wroclawskiej 1968 r., Referaty I: Wroclaw, 369380.

Šklje, L. (1969a). Rheological aspects of soil mechanics, p. 571. London: Wiley-Interscience.

Šuklje, L. (1969b). Consolidation of viscous soils subjected to continuously increasing uniform load. New advances in soil mechanics, vol. I, pp. 199-235. Prague: Czechoslovak Scientific and Technical Society.

Suklje, L. and Simončič, M. (1972). The use of isotaches in the numerical analysis of radial consolidation. University of Ljubljana, Acta Geotechnica, No. 41, 1-57.

Suklje, L. \& Kozak, J. (1972). Radially symmetric space consolidation of saturated viscous soils. University of Ljubljana, Acta Geotechnica, No. 42, 1-51.

\section{J. Garlanger}

The Writer raises two questions concerning the Paper which are as follows.

(a) What is the correct compressibility to use in determining the change in pore pressure with time during the consolidation process?

(b) How is the excess pore pressure that is induced in a saturated soil by one-dimensional, instantancous loading related to the applied total stress?

The answer to the first question is of paramount importance because a correct value for the compressibility of the soil structure is essential to the analysis. The solution to the following equation

$$
\frac{\partial e}{\partial t}=\frac{k\left(1+e_{0}\right)}{\gamma_{\mathrm{w}}} \frac{\partial^{2} \bar{u}}{\partial z^{2}}
$$

(which gives the rate of consolidation at any point within a soil mass free to drain in only one direction) is not possible without obtaining the distribution of pore pressures throughout the soil mass as a function of time during the entire consolidation process.

As discussed in the Paper, the change in pore pressure with time can be given as

$$
-\frac{\partial \bar{u}}{\partial t}=\frac{\frac{\partial e}{\partial t}-\left(\frac{\partial e}{\partial t}\right)_{c}}{\frac{\partial e}{\partial \bar{p}}}
$$

where $\partial e / \partial t$ is the consolidation rate given by equation $(1),(\partial e / \partial t)_{\mathrm{c}}$ is the rate of creep under constant effective stress and $\partial e / \partial \bar{p}$ is the compressibility of the soil structure. It can be seen from equation (2) that the rate of dissipation of pore pressure during consolidation is controlled 
by the creep rate and the compressibility of the soil structure. These two parameters must be determined together, i.e. they are not independent.

The Writer suggests that the creep rate and the consolidation rate may be set equal to each other giving $\partial u / \partial t \rightarrow 0$. This is certainly possible and probable during part of the consolidation process but is not generally true and should not be the basis for a solution of equation (1).

Consistent values of compressibility and creep rate are given by the Author's equations (8), (9) and (10) (the Writer's equations (6), (3) and (4) respectively). Equations (8) and (9) were obtained by assuming that a change in void ratio caused by a change in effective stress would occur as soon as the effective stress changed, i.e. at $t=0$.

However, it was realized after several solutions had been obtained, that equation (8)

$$
\frac{\partial e}{\partial \bar{p}}=\frac{a e}{\bar{p}}
$$

predominantly controlled the consolidation process, i.e. only the soil elements at the drainage boundary were ever loaded beyond the critical pressure, where the compressibility given by equation (7) was applicable. This is not surprising, because as the soil consolidates, it creeps and develops a reserve resistance to further compression (Bjerrum, 1967).

As it is not possible to separate creep from compressibility during a consolidation test, it is not possible to obtain exact values for the slope $a$ of the instant line between $p_{0}$ and $p_{c}$. The values used in the calculations were, of necessity, approximate. (See section on example of calculation for a discussion of how $a$ was chosen.) However, it is certainly not possible to assume, as the Writer suggests, that the soil structure is infinitely rigid $(a=0)$. A compressibility of zero would give a dissipation rate approaching infinity.

The concept of soil compressibility is important in the second question raised by the Writer concerning the relationship between excess pore pressure, $\Delta u$, and applied total stress, $\Delta \sigma$, for the conditions of one-dimensional, instant loading. This relationship, commonly expressed as the ratio $\Delta u / \Delta \sigma$, is given by the following equation (see Skempton, 1954 for its derivation)

$$
\mu=B=\frac{1}{1+n\left(c_{\mathrm{w}} / c_{\mathrm{s}}\right)}
$$

where $n$ is the porosity of the soil skeleton, $c_{\mathrm{w}}$ is the compressibility of water, and $c_{\mathrm{s}}$ is the compressibility of the soil structure. It is never possible for $B$ to have a value exactly equal to $1 \cdot 0$. The use of this value for $\mu$ in the calculations was only done for convenience. The theoretically correct value, with $a=0.010, p_{0}=1 \mathrm{~kg} / \mathrm{cm}^{2}$ and $e_{0}=1.4$, would have been 0.9977 .

It is also recognized that it is impossible to measure a value of $B$ exactly equal to the theoretically correct value. Such factors as the compressibility of the measuring system, leakage at the connexions, and air in the measuring system can all cause significant time dependent differences between measured and calculated pore pressures. (For a discussion of pore pressure measurements in soils, see Wissa (1968).)

However, it should be mentioned that the assumptions of instantaneous loading, uniform distribution of pore pressure throughout the specimen and a $B$ coefficient essentially equal to 1.0 were met by the laboratory specimens used to check the Author's calculations. However, it would have been possible and not difficult to include time dependent loading and nonuniform pore pressure distribution in the calculations if these conditions had been important.

\section{REFERENCES}

Bjerrum, L. (1967). Seventh Rankine Lecture. Engineering geology of normally-consolidated marine clays as related to settlements of buildings. Géotechnique 17, No. 2, 82-118.

Skempton, A. W. (1954). Pore pressure coefficients A and B. Géotechnique 4, No. 4, 143-147.

Wissa, A. E. Z. (1969). Pore pressure measurement in saturated stiff soils. Proc. Am. Soc. Civ. Engrs 95, SM4, 1063-1073. 